\title{
Prevalence and Risk of Blood-Borne and Sexually Transmitted Viral Infections in Incarcerated Youth in Salvador, Brazil: Opportunity and Obligation for Intervention
}

\author{
Margaret Fialho • Márcia Messias · Kimberly Page-Shafer · Lourdes Farre • \\ Márcia Schmalb · Diana Pedral-Sampaio · Mauro Ramos $\cdot$ Carlos Brites
}

Published online: 27 May 2008

(C) Springer Science+Business Media, LLC 2008

\begin{abstract}
To determine the prevalence of sexually transmitted and blood-borne infections among incarcerated adolescents in Salvador, Brazil, we interviewed 300 incarcerated youth aged 11-18 years to participate in a physical examination and to provide a blood sample to test for HIV-1, hepatitis B and C viruses exposure, human T-cells lymphotrophic virus, and syphilis. Overall prevalence was anti-HIV, 0.34\%; anti-HBc, $11.1 \%$; HBsAg, 2.4\%; anti-HCV, 6.4\%; HTLV, $1.09 \%$; and syphilis, $3.4 \%$. The majority $(86.3 \%)$ reported a history of sexual activity; $27 \%$ had never used condoms. Girls also reported previous pregnancy (35\%), abortion (26\%) and sexual abuse (74\%). Many youth reported a family history of alcohol abuse (56\%), illicit drug use (24.7\%), or legal problems (38\%). Serological results show that youth in Salvador are at high risk for blood-borne and sexually transmitted infections. Policies to reduce the risk and impact of these infections
\end{abstract}

M. Fialho - M. Messias - M. Schmalb

Centro de Referência do Estado da Bahia para AIDS

(CREAIDS), Salvador, Brazil

K. Page-Shafer

Center for AIDS Prevention Studies, University of California

San Francisco, San Francisco, CA, USA

L. Farre

Fundação Oswaldo Cruz (FIOCRUZ), Salvador, Brazil

D. Pedral-Sampaio - C. Brites $(\varangle)$

Infectious Diseases Service, Universidade Federal da Bahia Hospital, Rua João das Botas, SN, $6^{\circ}$. Andar, Canela, Salvador, Bahia 40110-160, Brazil

e-mail: crbrites@ufba.br

M. Ramos

Centro de Estudos em AIDS do Rio Grande do Sul (CEARGS),

Porto Alegre, Brazil should be a requisite part of health care for incarcerated youth.

Keywords Sexually transmitted infections · HIV ·

STI - Incarcerated youth · Brazil · Blood-borne infections

\section{Introduction}

In Brazil, according to the Bill of Rights of Adolescents and Children, youth and adolescents (up to age 18) who commit any crime or legal infraction can be sentenced to socio-educational penalties: counseling, reparation, community service, assisted freedom (not incarcerated but under court ordered adult/guardian supervision, semifreedom (wherein they spent daylight periods out of the institution, but must return at night; for instance for workfurlough), and confinement (Ministério da Justiça do Brasil 1990). When these penalties fail, children and youth may be detained in institutions. From 2000 to 2003 in Salvador, Brazil, 4,969 youth (including children and adolescents aged 12-21 years) were confined in youth detention centers. The primary reasons for detention of youth include petty theft and robbery, although they also are detained for assault and homicide (Tapparelli and Almeida 2003). The existence of this large number of detained children and their unmet social and health needs has become a public health crisis (Gurgel et al. 2004; Inciardi and Surratt 1998; Noto et al. 2003).

Detained children and adolescents primarily have streetliving circumstances, which is a serious social problem in resource-poor countries such as Brazil (Goodwin et al. 2004; Inciardi and Surratt 1998; Lockhart 2002; Tantoco 1993). In Latin America, estimates of the number of children and adolescents living in the streets varies from 
100,000 to 30 million (Lejeune 1993), and in Brazil there are no precise population estimates (Abdelgalil et al. 2004; Celia et al. 1993). Poverty, family instability and dysfunction arising from drug addiction and diverse forms of violence and sexual abuse, contribute to street living among children and adolescents. (Goodwin et al. 2004). Once youth are on the streets, many negative factors impact their health, including possible exposure to injection drugs and sexual activity, resulting in increased risk for acquisition of sexually and parenterally transmitted diseases (Abdelgalil et al. 2004; Filgueiras 2003; Iniciardi and Surratt 1998; Lockhart 2002; Martins et al. 1995; Porto et al. 1994; Raffaelli et al. 1993; Ribeiro 2003; Roy et al. 2001).

Inside the correctional institutions, health and heath care are generally poor; prevention, diagnosis, and treatment programs also are limited. Often, there is lack of resources, including basic supplies, such as medications, and simple diagnostics tests. Facilities commonly are overcrowded, enhancing the risk of acquisition and transmission of infectious diseases, including sexually transmitted infections (STIs) and infection with hepatitis B virus (HBV) and HIV (Libonatti et al. 1994; Miranda and Zago 2001; Pinto et al. 1994; Porto et al. 1994). Parenteral exposure from activities such as tattooing and piercing and use of intravenous drugs may increase the chances of dissemination of blood-borne pathogens such as HBV and hepatitis $\mathrm{C}$ virus (HCV), HIV, and human T-cell lymphotropic virus type 1 and 2 (HTLV-1 and -2), which are prevalent in this area of Brazil (Martins et al. 1995; Massad et al. 1999; Dourado et al. 2003). In Brazil, information on the prevalence of these infections among detained children and adolescents is scarce (Carvalho et al. 2006; Martins et al. 1995; Miranda and Zago 2001) due to ethical and operational challenges. We therefore present results from serological tests for exposure to $\mathrm{HIV}, \mathrm{HBV}, \mathrm{HCV}, \mathrm{HTLV}$ and Treponema pallidum (syphilis) from our study conducted in a sample of youth detained in a correctional institution in Salvador, Brazil.

\section{Methods}

Between May 2004 and March 2005 we conducted a crosssectional study assessing biological, psychological and social health factors in detained youth in Salvador, Brazil. As part of this study we assessed the prevalence of serological markers for HIV, HTLV, HBV, HCV, and syphilis (T. pallidum) infections. The research was conducted at the Casa de Acolhimento do Menor (CAM-Home for Admissions of Minors), a unit of the Fundação para a Criança e Adolescente (FUNDAC, Foundation for Children and Adolescents) in Salvador, Brazil. At the time we conducted this study, 300 youth of both sexes were being detained at CAM. We found no established routine for clinical or laboratory health evaluations for new detainees as they were admitted.

Sampling was consecutive, and all adolescents admitted and detained at CAM during the study period (May 2004 through March 2005) were invited to participate. The informed consent process included providing youth with detailed information on all the procedures as well as the risks, benefits and alternatives to study participation. Verbal consent was obtained in the presence of an independent adult witness who was not affiliated with CAM. To motivate the youth to participate in the study, and to attend to their need for information, weekly small-group (8-10 participants) discussions were offered on topics of health and sexuality, with emphasis on STI prevention, sexual and mental health, pregnancy, and illicit drug use. In addition, each participant received a kit containing personal hygiene products (e.g., toothbrush and tooth paste, comb) and a diary containing STI prevention recommendations developed and provided by the Brazilian Ministry of Health for distribution to adolescents. Entering the study was voluntary: participating youth were informed that they could stop at any time and that neither refusal nor participation would affect their standard of care or their legal status in the institution. Study participants were administered a structured survey by trained interviewers. The survey was adapted from the Form for Individual Attending of Adolescents, which is a component of a computer-based survey developed by the Latin American Center for Perinatology and Human Development (Simini et al. 1995). This tool includes a comprehensive bio-psycho-social evaluation, personal and family data on drug abuse, social life, behaviors, sexuality, previous medical history, and potential protective factors, such as self image, adult reference, and life goals.

A study physician conducted a complete physical examination, during which venous blood was drawn for serological testing. FUNDAC monitors were present during the study but remained outside the examination and interviewing rooms to maintain confidentiality. We collected $10 \mathrm{ml}$ of blood for serology tests (anti-HIV, AgHBs, anti$\mathrm{HBc}$, anti-HCV, anti-HTLV, and VDRL), which were sent for evaluation to the Retrovirology Laboratory at the University Hospital Professor Edgard Santos, Federal University of Bahia (UFBA). The serology tests for viral agents were performed by commercial enzyme immunoassay (EIA) tests, according to the manufacturer's instructions (Vironostika, Bio-Merieux, Rio de Janeiro, J, Brazil). Syphilis was detected using a quantitative VDRL test (Omega Diagnosis Ltd., Alva, Scotland). To avoid false-positive results, only dilutions of $\geq 1: 16$ were considered to be a positive test. Adolescents with serological 
evidence of HIV, HCV, HTLV or HBV infection, or with clinical symptoms, were seen by physicians at Health Services at UFBA Hospital or at the State of Bahia Referal Center for AIDS for additional evaluation and treatment. Other clinically evident STIs and syphilis were treated in loco, according to the recommendations of the National STD/AIDS Committee (Ministério da Saúde do Brasil 2000).

Descriptive statistics were generated, including means and medians for quantitative data and frequencies for categorical variables. Prevalence is expressed in percentages, and $95 \%$ confidence intervals were estimated based on binomial distributions. Bivariate associations between the primary outcomes (HIV, HCV, HTLV, HBV and syphilis) and exposures of interest, including demographic and psychosocial variables, were assessed using the chisquare statistic or Fisher exact test, when appropriate. Analyses are stratified by sex. Statistical analyses were performed using STATA (StataCorp LP; College Station, TX) The protocol and all procedures for the project were reviewed and approved by the Research Ethics Committee from the Federal University of Bahia, as well as by the presiding judge overseeing the Office of Infancy and Childhood.

\section{Results}

All invited adolescents $(n=300)$ consented to participate in the study, and 297 (99\%) agreed to venipuncture to obtain blood samples. Complete interview data were obtained from 268 (89.3\%) participants. Reasons for lack of interview data included transfer of adolescents to another unit and scheduling conflicts. The majority of participants $(91 \%)$ were male, median age was 17 years (interquartile range [IQR]: 11-18 years); median age for females $(n=24)$ was 16.5 (IQR, 12-17.5 years). Table 1 shows the prevalence of antibodies for the blood samples analyzed for infection and distributions by sex and age. Overall prevalence was $0.34 \%$ for anti-HIV, $6.4 \%$ for anti$\mathrm{HCV}, 11.1 \%$ for anti-HBc, $2.4 \%$ for $\mathrm{HBsAg}, 1.09 \%$ for HTLV-1, and $3.4 \%$ for syphilis. Positive VDRL test results, which is indicative of exposure to syphilis, was significantly associated with anti-HCV positivity $(\mathrm{OR}=5.16$; 95\% CI: $1.48-17.94, P<0.05$, Yates corrected), with positive HBsAg test results (OR $=14.1 ; 95 \%$ CI: 1.56-14.87, $P<0.01$, Yates corrected), and with a higher risk for infection with any other STI $(\mathrm{OR}=5.44$, 95\% CI: 1.29-24.1, $P<0.05$, Yates corrected).

Table 2 shows selected demographic characteristics and familial and social experiences, including drug and sexual history, among incarcerated youths stratified by sex and among the total sample. More than half $(56 \%)$ of

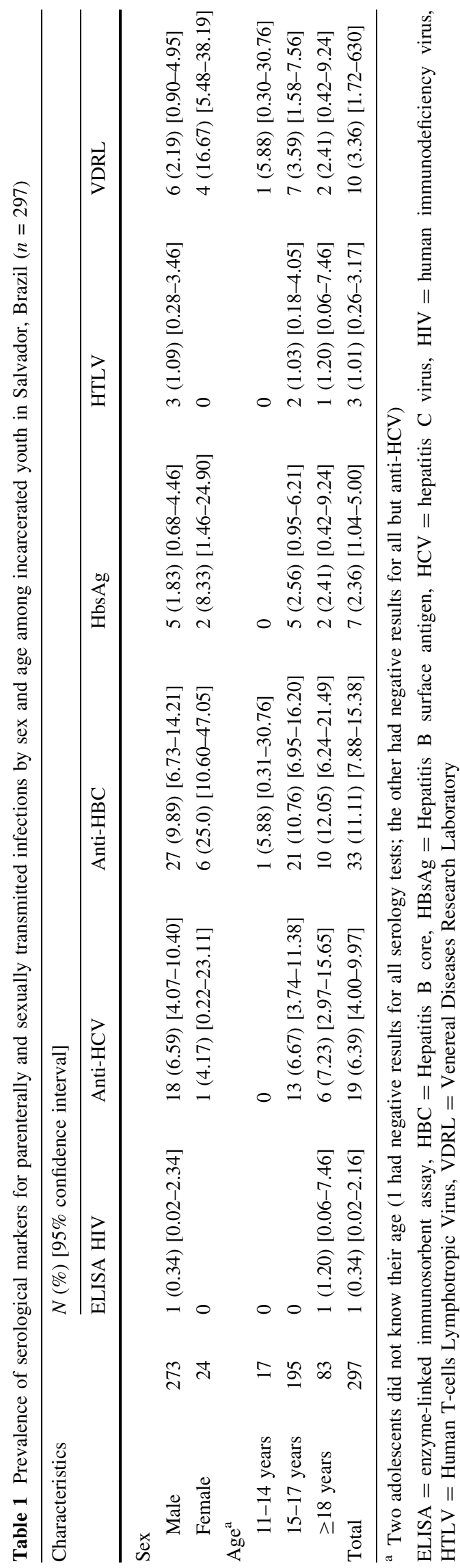


Table 2 Prevalence by sex of selected demographic characteristics reported experiences, and exposures among incarcerated youth in Salvador, Brazil ( $n=268)$

\begin{tabular}{|c|c|c|c|}
\hline \multirow[t]{2}{*}{ Characteristics, experiences, or exposures } & \multicolumn{2}{|l|}{$\begin{array}{l}\text { Male } \\
N(\%)\end{array}$} & Total \\
\hline & $245(9.4)$ & $23(8.6)$ & $268(100)$ \\
\hline Mean age, years $($ median $=17$ years) & 17.3 & 16.4 & 17.3 \\
\hline Steady sexual partner & $22(9.0)$ & $5(21.7)$ & $27(10.1)$ \\
\hline \multicolumn{4}{|l|}{ A family history of } \\
\hline Alcohol & $138(56.3)$ & $11(47.8)$ & $149(55.6)$ \\
\hline Illicit drugs & $56(23.5)$ & $8(38.1)$ & $64(24.7)$ \\
\hline Violence* & $78(32.6)$ & $12(57.1)$ & $90(34.6)$ \\
\hline Legal problems & $89(37.9)$ & $9(42.9)$ & $98(38.3)$ \\
\hline \multicolumn{4}{|l|}{ Education } \\
\hline Currently in school** & $176(73.0)$ & $21(95.5)$ & $197(74.9)$ \\
\hline School evasion & $151(61.6)$ & $13(56.5)$ & $164(61.2)$ \\
\hline Never attended school & $16(6.6)$ & 0 & $16(6.1 \%)$ \\
\hline \multicolumn{4}{|l|}{ Social insertion } \\
\hline Currently have a boy/girlfriend & 169 (70.7) & $13(56.5)$ & $182(69.5)$ \\
\hline Currently have friends & $186(78.5)$ & $19(82.6)$ & $205(78.8)$ \\
\hline \multicolumn{4}{|l|}{ Past or current use of illicit drugs } \\
\hline Tobacco & $202(84.2)$ & $22(95.7)$ & $224(85.2)$ \\
\hline Alcohol & $136(57.9)$ & $15(65.2)$ & $151(58.3)$ \\
\hline Glue & $36(15.1)$ & $5(21.7)$ & $41(15.7)$ \\
\hline Solvent & $19(8.0)$ & $5(21.7)$ & $24(9.2)$ \\
\hline Marijuana & $162(68.1)$ & $16(69.5)$ & $178(68.2)$ \\
\hline Crack & $64(26.9)$ & $7(30.4)$ & $71(27.2$ \\
\hline Inhaled cocaine & $66(27.7)$ & $6(26.1)$ & $72(27.6)$ \\
\hline Injected cocaine & $1(0.4)$ & $1(0.4)$ & $2(0.74)$ \\
\hline \multicolumn{4}{|l|}{ Previous history of } \\
\hline STI & $57(24.1)$ & $11(50.0)$ & $68(26.3)$ \\
\hline Pregnancy**** & - & $8(34.8)$ & - \\
\hline Children & $33(13.7)$ & $5(21.7)$ & $38(14.4)$ \\
\hline Abortion**** & - & $6(26.1)$ & - \\
\hline Sexual abuse* & $18(7.8)$ & $17(73.9)$ & $35(13.7)$ \\
\hline \multicolumn{4}{|l|}{ Sexuality*** } \\
\hline Mean age of sexual debut (IQR) & $13.5(13-18)$ & $18.8(11-17)$ & $13.4(13-18$ \\
\hline \multicolumn{4}{|l|}{$\mathrm{N}$ of lifetime sexual partners } \\
\hline 0 (zero) partners & $19(7.7$ & $0(0)$ & $19(7.7)$ \\
\hline One partner & $67(31.8)$ & $4(19.0)$ & $71(30.6)$ \\
\hline$\geq 2$ partners & $144(68.2)$ & $17(81.0)$ & $161(69.4)$ \\
\hline \multicolumn{4}{|l|}{ Sexual partnerships } \\
\hline Heterosexual & $194(85.8)$ & $13(56.5)$ & $207(83.1)$ \\
\hline Bisexual & $28(12.4)$ & $8(34.8)$ & $36(14.5)$ \\
\hline Homosexual & $4(1.8)$ & $2(8.7)$ & $6(2.4)$ \\
\hline \multicolumn{4}{|l|}{ History of condom use } \\
\hline Always & $40(17.9)$ & $4(17.4)$ & $44(17.9)$ \\
\hline Sometimes & $121(52.2)$ & $12(52.2)$ & $133(52.2)$ \\
\hline Never used & $62(27.8)$ & $7(30.4)$ & $69(28.0)$ \\
\hline \multicolumn{4}{|l|}{ Currently have a supportive adult in their life } \\
\hline Father & $29(11.8)$ & 4 (17.4) & $33(12.3)$ \\
\hline Mother & $61(24.9)$ & $2(8.7)$ & $63(23.5)$ \\
\hline
\end{tabular}


Table 2 continued

\begin{tabular}{|c|c|c|c|}
\hline \multirow[t]{2}{*}{ Characteristics, experiences, or exposures } & \multicolumn{3}{|l|}{$N(\%)$} \\
\hline & $245(9.4)$ & $23(8.6)$ & $268(100)$ \\
\hline Other relative & $47(19.2)$ & $3(13.0)$ & $50(18.7)$ \\
\hline Out of family & $19(7.8)$ & $3(13.0)$ & $22(8.2)$ \\
\hline Absent & $77(31.4)$ & $11(47.8)$ & $88(32.8)$ \\
\hline \multicolumn{4}{|l|}{ Life ambitions } \\
\hline Clear & $142(61.5)$ & $10(43.5)$ & $152(59.8)$ \\
\hline Confuse & $58(25.1)$ & $10(43.5)$ & $68(26.8)$ \\
\hline Absent & $31(13.4)$ & $3(13.0)$ & $34(113.4)$ \\
\hline \multicolumn{4}{|c|}{$\mathrm{IQR}=$ interquartile range, $\mathrm{STI}=$ sexually transmitted infection } \\
\hline \multicolumn{4}{|c|}{$* P$-value $<0.05$ for comparisons between proportions of male versus female participants } \\
\hline \multicolumn{4}{|l|}{$* *$ Currently studying in the institution } \\
\hline \multicolumn{4}{|c|}{ *** Those who remember the age of sexual initiation $(\mathrm{n}=216)$} \\
\hline$* * * *$ Only girls included in analysis & & & \\
\hline
\end{tabular}

participants reported problematic use of alcohol by parents or parental substitutes, such as step-parent, grandparent, other family member acting as a parent, or foster parent). Over one-third $(37 \%)$ of youth reported illicit drug use by parents or parental substitutes, and, similarly, domestic violence $(34 \%)$, and legal problems (37\%, including incarceration or prosecution) of at least one family member). One-third (33\%) of participants reported that they could not identify a supportive adult in their life: they had no parents or substitute parents and no identifiable social support outside the correctional institution. The majority $(86.6 \%)$ of youth reported being sexually active, $63.1 \%$ reported multiple $(\geq 2)$ sexual partners during their lifetime (74\% of girls and $62 \%$ of boys). Median reported age of sexual initiation was 13 years (IQR: 11-15 years) for girls and 14 years (IQR: 13-15 years) years for boys; $44(17 \%)$ of sexually active youth reported consistent use (always use) of condoms, and half (52\%) reported using condoms "sometimes." There were no differences in condom use among youth who reported one compared with multiple sexual partners during their lifetime. Overall, 25\% of participants reported having been diagnosed previously with an STI by a health care practitioner. Among girls $(n=24)$, $17(74 \%)$ reported sexual abuse (i.e., any non-consensual sex, usually with use of physical coercion), 11 (48\%) had been previously diagnosed with an STI, 8 (35\%) had at least one previous pregnancy, and $5(22 \%)$ had at least one baby. Abortion was reported by $6(26 \%)$ of the girls.

Youth who reported using condoms in all sexual relationships, compared with those who did not, had a significantly lower probability of reporting a previous STI (OR $=0.06 ; 95 \%$ CI: $0.01-0.61, P<0.01$, Yates corrected). However, no associations were found between reported condom use and any of the outcomes tested by serology. Participants who reported being sexually active ( $\geq 1$ sexual partner during lifetime) were significantly more likely to have positive test results for $\mathrm{HBsAg}(5.6 \%)$ compared with participants $(0.6 \%)$ who reported no sexual partner $(\mathrm{OR}=9.45 ; 95 \% \mathrm{CI}: 1.03,79.72, P<0.05$, Fisher exact test). Self-reported illicit drug use also was not associated with any of the outcomes of serological tests (data not shown).

\section{Discussion}

This study provides two main contributions to the current knowledge of health and prevalence of infectious disease among incarcerated adolescents in Brazil. First, was the greater-than-expected evidence of exposure to $\mathrm{HCV}$ and $\mathrm{HBV}$ infections. Prevalence of HCV infection was higher $(11 \%)$ than that seen in young Brazilian army conscripts $(1.5 \%)$, who are older (17-22 years) and who have had more potential exposure time (Toledo et al. 2005). Prevalence of HBV antigenemia, however, was identical for both groups $(2.6 \%)$. Similarly, the prevalence for the marker for HBV was comparable to that found among street youth in central Brazil, where $13 \%$ had a positive marker for $\mathrm{HBV}$ infection (Porto et al. 1994). Prevalence of HTLV-I infection and syphilis were similar to those found in adult groups (age 18-30 years) in Salvador (de Codes et al. 2006; Dourado et al. 2003). These findings, however, in such a young population demonstrate a very high risk of both parenteral and sexual exposure to infection, likely in association with drug user, parenteral exposure and high rates of unprotected sex. HIV infection was found in only 1 participant, but given the number and proportion of $\mathrm{HCV}$ and HBV infections, both far more infectious agents, these 
findings suggest that this population is highly vulnerable to infection with HIV due both to shared routes of infection and transmission exposure risk, but also the high likelihood that they will mix socially and sexually with older groups with potentially higher prevalence of HIV. As this population ages and mixes with other higher prevalence groups, these youth are at risk for HIV acquisition, especially given the prevalence of unprotected sex they reported. High sexual risk for HIV is also indicated by the other findings of this survey, especially those for syphilis, which has been shown to be an independent risk factor for HIV in previous studies (Alves et al. 2003; Marins et al. 2000). The second main finding is that a high proportion of these youth are highly vulnerable psychosocially: a significant number report exposure to family violence, excessive alcohol and drug use, and, among girls, significant rates of pregnancy and sexual abuse. Many of these factors have been associated with increased vulnerability for HIV infection (De Moura et al. 2003; De Moura. 2004; Libonatti et al. 1994; Noto et al. 2003).

After extensive review of the literature, we found only two other studies regarding exposure to HIV, hepatitis and syphilis infection among incarcerated youth in São Paulo and Vitória, two large Brazilian cities (Carvalho et al. 2006; Miranda and Zago 2001). In both studies, samples sizes were smaller than the groups we studied here $(n=83$ and $n=103$, respectively). Low HIV prevalence was consistent between our sample $(0.34 \%)$ and that in São Paulo (1\%), but much higher in Vitória (4.9\%). Markers of HBV exposure (anti-HBC or HBsAg) were slightly higher in São Paulo (16\%) compared with our sample (13.5\%) Prevalence of HCV also was consistent in ours and the São Paulo study (6\%), but this marker was not assessed in Vitória. Markers for syphilis infection in São Paulo (8.5\%) and Vitória (7.8\%) also were higher compared with our study (3.4\%). Neither study assessed HTLV infection status. Our sample had a markedly lower proportion of participants reporting intravenous drug use $(0.74 \%)$ compared with the São Paulo and Vitória samples (10 and $10.7 \%$, respectively). No studies have previously reported on prevalence of HTLV in this population. The association between VDRL positivity and active HBV in this study, confirming the finding in the São Paulo sample, demonstrated the need for STI prevention and treatment in these youth. Unlike the São Paulo study, we found no associations between $\mathrm{HCV}$ and intravenous drug use, which probably can be explained by the low rates of intravenous drug use reported by participants in our study.

Others studies have assessed HIV and HBV infection markers in youth living in the streets in other Brazilian cities (Porto et al. 1994; Pinto et al. 1994). The prevalence of $\mathrm{HBV}$ markers in Central Brazil was comparable with that of our study (13.5\% for anti-HBC and $2 \%$ for HBsAg).
These results from the early 1990s and the comparable rates found in our study and the previous studies in incarcerated youth suggest that HBV vaccination programs have not been effectively targeted toward youth. The sociodemographic and family histories of incarcerated youth and youth in street circumstances are similar, with a common theme of domestic violence, sexual abuse, and absence of parents or parent substitutes. These and other factors that combine to push youth to street-living situations and, for some, to eventual incarceration, require immediate social and public health attention.

Limitations to our data include modest sample size, which potentially limits the statistical power of our results. In addition, this sample is from one institution and may not be representative of all incarcerated adolescents in Bahia or Brazil. However the comparability of our results with those of other studies with smaller samples sizes show some consistency across regions. The paucity of biological and behavioral data from adolescents in Brazil, and especially from those incarcerated, however, requires that these results be viewed as indicative of a public health crisis. The use of VDRL as a marker for syphilis could be questioned, as it is a nonspecific test, but it has been used widely as a reliable, highly sensitive diagnostic test for syphilis (Larsen et al. 1995). Cross-reaction with other clinical conditions is not a common finding but may occur in patients presenting with autoimmune diseases (Larsen et al. 1995). Usually, cross-reactions result in a lower dilution positive reaction. The quantitative test used, with a higher cut off, reduces the risk of false-positive results, as low reactivity was not considered as a defined diagnosis.

\section{Conclusions}

Within correctional facilities, there is often conflict between the objectives for safety and control of the confined populations and the goals for health care. As a result there is often great inconsistency and unpredictability in the programmatic health care, including prevention and intervention programs, delivered to incarcerated populations. In this study, our data show that incarcerated adolescents are highly vulnerable and at high risk for bloodborne and sexually transmitted infections. Most significantly, these data show the great opportunity to introduce intervention measures. Because incarcerated youth is a confined population, serological testing coupled with preand post-test counseling, routine immunization against hepatitis B, and ready treatment for syphilis all could contribute to control the spread of these infections and provide opportunities for other risk- and harm-reduction education. In addition, providing access to contraceptive methods and condoms is an important and necessary health measure that 
must be introduced. Educational interventions on risk and prevention of STIs appear to be essential as well (Peres et al. 2002). There is considerable opportunity and obligation to deliver essential health and preventive care to detained youth, and especially to institute public policies aimed at reducing the risk and impact of STIs and HIV infections on this young population. We propose that health, including social, mental and physical health, be prioritized as a human rights issue among incarcerated youth.

Acknowledgments We thank all the professionals working at CAM, especially Ajurimar Maia Montenegro, and the Judge for Infancy and Youth, Dr. Nelson Santana do Amaral, for their support to our work. This work was supported by a grant from Brazilian National AIDS ProgramMinistry of Health. We also would like to acknowledge the University of California, San Francisco, Center for AIDS Prevention Studies (NIMHP30 MH062246), the International Clinical, Operational and Health Services Research Training Award (ICOHRTA), Brazil Scientists Program, Fogarty International Center (D43TW005799), and AIDS International Training in Research Program (AITRP), Fogarty International Center, D43TW00003 for support.

\section{References}

Abdelgalil, S., Gurgel, R. G., Theobald, S., \& Cuevas, L. E. (2004). Household and family characteristics of street children in Aracaju, Brazil. Archives of Disease in Childhood, 89(9), 817820. doi:10.1136/adc.2003.032078.

Alves, K., Shafer, K. P., Caseiro, M., Rutherford, G., Falcao, M. E., Sucupira, M. C., et al. (2003). Risk factors for incident HIV infection among anonymous HIV testing site clients in Santos, Brazil: 1996-1999. Journal of Acquired Immune Deficiency Syndromes, 32(5), 551-559. doi:10.1097/00126334-20030415000014.

Carvalho, F. T., Neiva-Silva, L., Ramos, M. C., Evans, J., Koller, S. H., Piccinini, S. A., et al. (2006). Sexual and drug use risk behaviors among children and youth in street circumstances in Porto Alegre, Brazil. AIDS and Behavior, 10, S57-S66. doi:10.1007/s10461006-9124-4.

Celia, S., Alves, M., Behs, B., Nudelmann, C., \& Saraiva, J. (1993). The effects of violence on infants and young children: International perspectives on prevention. Infant Mental Health Journal, 14(2), 96-102. doi:10.1002/1097-0355(199322)14:2 $\leq 96:: A I D-$ IMHJ2280140203 $\geq 3$.0.CO;2-E.

De Codes, J. S., Coghen, D. A., Melo, N. A., Teixeira, G. G., Leal, A. S., Silva, T. J., et al. (2006). Detecção de doenças sexulamente transmissíveis em ambientes clínicos e não clínicos na cidade de salvador, Bahia, Brazil. Cadernos de Saúde Pública, 22(2), 325-334.

De Moura, S. L., Harpham, T., \& Lyons, M. (2003). The social distribution of explanations of health and illness among adolescents in Sao Paulo, Brazil. Journal of Adolescence, 26(4), 459473. doi:10.1016/S0140-1971(03)00030-7.

De Moura, S. L. (2004). The social distribution of reports of healthrelated concerns among adolescents in Sao Paulo, Brazil. Health Education Research, 19(2), 175-184. doi:10.1093/her/cyg023.

Dourado, I., Alcantara, L. C., Barreto, M. L., da Gloria Teixeira, M., \& Galvão-Castro, B. (2003). HTLV-I in the general population of Salvador, Brazil: A city with African ethnic and sociodemographic characteristics. Journal of Acquired Immune Deficiency Syndromes, 34(5), 527-531. doi:10.1097/00126334-20031215000013.
Filgueiras, A. (1993). Needs of Rio street children. Planned Parenthood Challenges, 2, 22-24.

Goodwin, R., Kozlova, A., Nizharadze, G., \& Polyakova, G. (2004). HIV/AIDS among adolescents in Eastern Europe: Knowledge of HIV/AIDS, social representations of risk and sexual activity among school children and homeless adolescents in Russia, Georgia and the Ukraine. Journal of Health Psychology, 9(3), 381-396. doi:10.1177/1359105304042348.

Gurgel, R. Q., da Fonseca, J. D., Neyra-Castaneda, D., Gill, G. V., \& Cuevas, L. E. (2004). Capture-recapture to estimate the number of street children in a city in Brazil. Archives of Disease in Childhood, 89(3), 222-224. doi:10.1136/adc.2002.023481.

Inciardi, J. A., \& Surratt, H. L. (1998). Children in the streets of Brazil: Drug use, crime, violence, and HIV risks. Substance Use and Misuse, 33(7), 1461-1480.

Larsen, A. S., Steiner, B. M., \& Rudolph, A. H. (1995). Laboratory diagnosis and interpretation of tests for syphilis. Clinical Microbiology Reviews, 8(1), 1-21.

Lejeune, G. (1993). Millions of children stricken by AIDS. Children Worldwide, 20(2-3), 3.

Libonatti, O., Casanueva, E., Avila, M. M., Gomez Carrillo, M., Piccardo, C., Cammarieri, G., et al. (1994). HIV-1 and HBV infection in street youth lodged in security institutes of Buenos Aires. Journal of Acquired Immune Deficiency Syndromes, 7(1), 98-100.

Lockhart, C. (2002). Kunyenga, "real sex", and survival: assessing the risk of HIV infection among urban street boys in Tanzania. Medical Anthropology Quarterly, 16(3), 294-311. doi: 10.1525/maq.2002.16.3.294.

Marins, J. R., Page-Shafer, K., Barros, M. B. A., Hudes, E. S., Chen, S., \& Hearst, N. (2000). Seroprevalence and risk factors for HIV infection among incarcerated men in Sorocaba, Brazil. AIDS and Behavior 4(1). doi:10.1023/A:1009501227346.

Martins, R. M., Porto, S. O., Vanderborght, B. O., Rouzere, C. D., Queiroz, D. A., Cardoso, D. D., et al. (1995). Short report: Prevalence of hepatitis C viral antibody among Brazilian children, adolescents, and street youths. American Journal of Tropical Medicine and Hygiene, 53(6), 654-655.

Massad, E., Rozman, M., Azevedo, R. S., Silveira, A. S., Takey, K., Yamamoto, Y. I., et al. (1999). Seroprevalence of HIV, HCV and syphilis in Brazilian prisoners: Preponderance of parenteral transmission. European Journal of Epidemiology, 15(5), 439445. doi:10.1023/A:1007523027876.

Ministério da Justiça do Brasil. (1990). Estatuto da Crianca e do Adolescente. Lei deleg 8.069, de 13 de julho de 1990

Ministério da Saúde do Brasil. (2000). Doenças sexualmente transmissíveis: manual de bolso (pp. 13-14).

Miranda, A. E., \& Zago, A. M. (2001). Prevalence of HIV infection and Syphilis among adolescentes in a juvenile justice System. Jornal Brasileiro de Doenças Sexualmente Transmissiveis, 13(4), 35-39.

Noto, A. R., Galduróz, J. C. F., Nappo, S. A., Fonseca, A. M., Carlini, M. A., \& Moura, Y. G. (2003). Levantamento nacional sobre o uso de drogas entre crianças e adolescentes em situação de rua nas 27 capitais brasileiras - 2003. São Paulo: Escola Paulista de Medicina.

Peres, C. A., Peres, R. A., da Silveira, F., Paiva, V., Hudes, E. S., \& Hearst, N. (2002). Developing an AIDS prevention intervention for incarcerated male adolescents in Brazil. AIDS Education and Prevention, 14(5 Suppl B), 36-44. doi:10.1521/aeap.14.7.36. 23858.

Pinto, J. A., Ruff, A. J., Paiva, J. V., Antunes, C. M., Adams, I. K., Halsey, N. A., et al. (1994). HIV risk behavior and medical status of underprivileged youths in Belo Horizonte. Brazil. Journal of Adolescent Health, 15(2), 179-185. doi: 10.1016/1054-139X(94)90547-9. 
Porto, S. O., Cardoso, D. D., Queiróz, D. A., Rosa, H., Andrade, A. L., Zicker, F., et al. (1994). Prevalence and risk factors for HBV infection among street youth in central Brazil. Journal of Adolescent Health, 15(7), 577-581. doi:10.1016/1054-139X (94) 90142-P.

Raffaelli, M., Campos, R., Merritt, A. P., Siqueira, E., Antunes, C. M., \& Parker, R. (1993). Sexual practices and attitudes of street youth in Belo Horizonte, Brazil Street Youth Study Group. Social Science \& Medicine, 37(5), 661-670. doi:10.1016/ 0277-9536(93)90105-D.

Ribeiro, M. O. (2003). The street: A deceitful shelter to the children living in it. Revista Latino-Americana de Enfermagem, 11(5), 622-629. doi:10.1590/S0104-11692003000500009.

Roy, E., Haley, N., Leclerc, P., Boivin, J. F., Cedras, L., \& Vincelette, J. (2001). Risk factors for hepatitis C virus infection among street youths. CMAJ, 165(5), 557-560.
Simini, E., Giacomini, H., \& Pasqualini, D. (1995). Adolescent information system. Guide lines for integral adolescent health care: clinical, social, psicoemotional, habits, gynaecology, etc. Instructions to fill in the clinical forms and for data entry and analysis with SIA software (1st ed.).

Tantoco, F. G. (1993). Philippines: Street children, children at risk. Children Worldwide, 20(2-3), 35-37.

Tapparelli, G., Almeida, A. (2003). Perfil dos adolescentes em conflito com a lei representados pela Promotoria de Justica da Infancia e da Juventude de Salvador (2000 a 2003). In Centro de Apoio Operacional as Promotorias de Justica da Infancia e da Juventude.

Toledo, A. C., Jr., Greco, D. B., Felga, M., Barreira, D., Gadelha, M. F., \& Speranza, F. A. (2005). Seroprevalence of hepatitis B and Cin Brazilian army conscripts in 2002: A cross-sectional study. The Brazilian Journal of Infectious Diseases, 9(5), 374-383. doi: 10.1590/S1413-86702005000500004. 